\title{
Outcome of first-episode schizophrenia in India: longitudinal study of effect of insight and psychopathology
}

\author{
Balasubramanian Saravanan, K. S. Jacob, Shanthi Johnson, Martin Prince, Dinesh Bhugra \\ and Anthony S. David
}

\section{Background}

Transcultural studies have found lack of insight to be an almost invariable feature of acute and chronic schizophrenia, but its influence on prognosis is unclear.

\begin{abstract}
Aims
To investigate the relationship between insight,

psychopathology and outcome of first-episode schizophrenia in Vellore, India.
\end{abstract}

\section{Method}

Patients with a DSM-IV diagnosis of schizophrenia $(n=131)$ were assessed prospectively at baseline and at 6-month and 12-month follow-up. Demographic and clinical measures included insight, psychopathology, duration of untreated psychosis (DUP) and social functioning. Linear and logistic regression was used to measure predictors of outcome.

\section{Results}

Follow-up data were available for 115 patients at 1 year. All achieved remission, half of them with and half without residual symptoms. Changes in psychopathology and insight during the first 6 months and DUP strongly predicted outcome (relapse or functional impairment), controlling for baseline measures.

\section{Conclusions}

Outcome of schizophrenia in this setting is driven by early symptomatic improvement and is relatively favourable, in line with other studies from low- and middle-income countries. Early improvement in insight might be a useful clinical guide to future outcome. Reduction of DUP should be a target for intervention.

\section{Declaration of interest}

None.
Transcultural studies of schizophrenia conducted under the auspices of the World Health Organization found that lack of insight was an almost invariable feature of acute and chronic schizophrenia, regardless of setting. ${ }^{1,2}$ A categorical or unidimensional view of insight has given way to more multidimensional perspectives, ${ }^{3}$ which appear to be adaptable to different cultural settings. ${ }^{4,5}$ In the past decade, instruments with more sensitivity than single-item measures have been devised to assess and quantify insight for research purposes, and important associations with psychopathological, social and biological factors have been replicated. ${ }^{3}$

Regarding the relation between insight and outcome of schizophrenia, studies of prevalent cases are generally uninformative since they tend to be biased towards patients with poorer outcomes. Prospective studies are less common, although the results tend to point towards better insight being associated with better prognosis. ${ }^{6}$ However, these studies suffer from the use of a wide variety of unvalidated insight scales and variable outcome measures. ${ }^{7}$ A few studies have explored insight as a predictor of outcome in first-episode psychosis. ${ }^{8-10}$ For example, David et al showed that a single insight item predicted employment status over 2 years in a recent-onset mixed psychosis cohort from south London. ${ }^{8}$ Drake et al showed that self-rated insight was a significant predictor of readmission over an 18-month period. ${ }^{10}$

We investigated prospectively a cohort of patients with a first episode of schizophrenia in Vellore, South India (see our earlier study). ${ }^{5}$ We sought to determine whether insight assessed on admission, or early improvement in insight, predicted good outcome independently of duration of untreated psychosis (DUP) and demographic factors such as gender, and whether any such change is associated with or independent of change in psychopathologic symptoms.

\section{Method}

In a prospective, longitudinal cohort study, data were collected on insight, psychopathology and 1-year course of schizophrenia in consecutive patients making their first contact with mental health services. Three assessments were undertaken: at baseline and at 6 months and 12 months. Our analysis used the baseline and follow-up data.

\section{Study site}

Tamil Nadu is one of the most industrialised states in India. The primary language is Tamil. Tamil Nadu has better education, health and development indices than most other Indian states: $73 \%$ of the population is literate compared with $65 \%$ for the whole country. ${ }^{11}$ Vellore district (area $4314 \mathrm{~km}^{2}$, population 3026432 ) is situated in the north central part of the state. Kaniyambadi Block, one of 12 administrative blocks in Vellore district, was the study site. The study took place in the Department of Psychiatry of the Christian Medical College, Vellore. The 100-bed hospital adult psychiatry unit provides short-term care for patients with different organic disorders, substance use, psychoses, neuroses and adjustment problems. The emphasis is on a multidisciplinary approach and eclectic care using a wide variety of therapies. The hospital has a daily out-patient clinic serving 200-250 patients.

\section{Sample and procedure}

The study group consisted of patients living within a $100 \mathrm{~km}$ radius of the study site. Patients were carefully screened for a diagnosis of schizophrenia and then interviewed by a research 
psychiatrist (B.S.) at intake using the Structured Clinical Interview for DSM-III-R - Patient version (SCID-P) to confirm the diagnosis. ${ }^{12}$ Patients with a primary diagnosis of substance use disorder, mood disorder or organic mental disorder were excluded (for details see reference 5). Patients meeting inclusion criteria and providing written consent were interviewed as soon as possible, with all patients assessed within a week of starting treatment for psychosis. All patients were interviewed again 6 months and 12 months after the initial assessment. Patients were informed that the purpose of the study was to assess their level of awareness about their illness, but they were unaware of the study's specific hypotheses.

\section{Assessment measures}

Social and demographic variables were recorded, including years of education. Patients were interviewed by trained raters using the Tamil version of SCID-P. At baseline we used the Lifetime version of the interview. The Schedule for the Assessment of Insight - Expanded version (SAI-E) with its three dimensions (awareness of illness, relabelling and compliance), the Brief Psychiatric Rating Scale (BPRS) and the Global Assessment of Functioning (GAF) were used at baseline and at each follow-up wave. ${ }^{8,13-15}$ As before, we used the 'guilt', 'low mood' and 'suicidality' items of the BPRS added together as a proxy measure of depression. Duration of untreated psychosis was defined as the interval from the occurrence of prominent psychotic symptoms to first contact with psychiatric services. This onset date was synthesised from the SCID-P interview, which included chronology of psychotic symptoms and significant other collateral information. Finally, whether or not the patient consulted a traditional healer prior to coming to the hospital was noted as a potential indicator of early illness awareness.

We planned to use clinically defined 'broad' psychosis outcomes (full remission, remission with deficits, and relapse) as the primary outcome measure, in addition to the repeated measures of GAF (baseline, 6-month and 12-month assessments). Remission is a state following a psychotic episode in which there is no positive or negative symptom for at least 30 days; relapse is the occurrence of at least one positive symptom or two negative symptoms after a period of remission; remission with deficits is the presence of one negative symptom or of social or occupational deficits after a period of remission. Two of the researchers (B.S. and K.S.J.) agreed on the ratings of remission and relapse, basing these on criteria used in the Study of Factors Associated with the Course and Outcome of Schizophrenia (SOFACOS), ${ }^{16,17}$ and the Determinants of Outcome of Severe Mental Disorders $(\mathrm{DOSMeD}),{ }^{18}$ applied to information extracted from clinical case notes. We used the broad psychosis outcome to tabulate the regression models to make this study more relevant to clinical practice in low- and middle-income countries.

\section{Statistical analysis}

The three broad psychosis outcome variables were collapsed to yield two: remission and relapse. Remission was defined as being symptom-free, and relapse was defined as meeting criteria for a schizophrenic episode after meeting criteria for remission in a previous follow-up period. We used general linear modelling (GLM) analysis in SPSS version 15 for Windows, to test whether baseline insight or psychopathology (BPRS score, model 1), or change in insight or psychopathology at 0-6 months (model 2) or at 6-12 months (models 3 and 4) predicted good outcome using GAF score as a continuous outcome measure at 12 months, controlling for sociodemographic and clinical variables (gender, marital status, employment, urbanicity, DUP, traditional healer visit plus baseline insight and psychopathology scores where appropriate). A second set of logistic regressions, each with the same model structure as above, was performed with clinical outcome (complete remission or relapse) as the dependent variable, entering the same independent variables and with the same controls. Interactions between insight and outcome and significant covariates were checked in the modelling. Model fits were checked by examining partial residual plots.

\section{Results}

Of 196 patients with first-episode psychosis who attended hospital clinics between 1 January 2003 and 30 January 2004, a total of 188 met the study criteria. Of these patients, 57 were excluded ( 37 owing to psychopathology precluding interview), 14 did not attend interview and 6 refused. Baseline interviews were administered to the 131 remaining consecutive patients who met the inclusion criteria. Of these patients, 72 (55\%) were men and 59 (45\%) were women, of mean age 29.5 years $($ s.d. $=7.2)$. Most were single $(48 \%)$, unemployed $(70 \%)$, lived in rural areas $(80 \%)$ during intake and had been brought to hospital by relatives (Table 1). The DUP was long and the distribution skewed (mean 95.5 weeks, median 48, range 2-720). The vast majority of patients were treated with olanzapine $(10-15 \mathrm{mg})$. The main findings from the baseline data have been published elsewhere. ${ }^{5,19}$

At 6 months, 103 (79\%) patients were interviewed and 115 $(88 \%)$ were assessed at the end of 1 year. The baseline, 6-month and 12-month follow-up mean scores on the BPRS, GAF and SAI-E scales showed general improvement in all clinical measures, as expected (Table 2). Interestingly, it appears that the greatest improvement in BPRS and GAF scores occurred within the first 6 months, whereas insight improved at a steadier rate over 12 months (Fig. 1).

Table 1 Patient characteristics at baseline and at 12-month follow-up

\begin{tabular}{|c|c|c|}
\hline & $\begin{array}{l}\text { Baseline } \\
\text { assessment } \\
(n=131)\end{array}$ & $\begin{array}{l}\text { 12-month } \\
\text { follow-up } \\
(n=115)\end{array}$ \\
\hline Age, years: mean (s.d.) & $29.5(7.2)$ & $29.5(7.0)$ \\
\hline \multicolumn{3}{|l|}{ Gender, $n$ (\%) } \\
\hline Male & $72(55)$ & $62(54)$ \\
\hline Female & $59(45)$ & $53(46)$ \\
\hline \multicolumn{3}{|l|}{ Religion, ${ }^{\mathrm{a}} \mathrm{n}(\%)$} \\
\hline Hindu & $115(88)$ & $102(89)$ \\
\hline Muslim & 4 (3) & $2(2)$ \\
\hline Christian & $11(8)$ & $10(9)$ \\
\hline \multicolumn{3}{|l|}{ Residence, $n$ (\%) } \\
\hline Rural & $105(80)$ & $92(80)$ \\
\hline Urban & $26(20)$ & $23(20)$ \\
\hline \multicolumn{3}{|l|}{ Literacy, $n$ (\%) } \\
\hline Illiterate & $22(17)$ & $18(16)$ \\
\hline Read only & $9(7)$ & $7(6)$ \\
\hline Read and write & $100(76)$ & $90(78)$ \\
\hline Age at onset of illness, years: mean (s.d.) & $27.8(6.8)$ & $27.9(6.8)$ \\
\hline $\begin{array}{l}\text { Duration of untreated psychosis, weeks: } \\
\text { mean (s.d.) }\end{array}$ & 95.5 (134.2) & $94.6(127.4$ \\
\hline \multicolumn{3}{|l|}{ Status, $n(\%)$} \\
\hline Brought by relatives & $115(88)$ & $104(90)$ \\
\hline Self-presenting & $16(12)$ & $11(10)$ \\
\hline
\end{tabular}




\begin{tabular}{|c|c|c|c|}
\hline & $\begin{array}{c}\text { Baseline } \\
\text { assessment } \\
\text { Mean (s.d.) }\end{array}$ & $\begin{array}{l}\text { 6-month } \\
\text { follow-up } \\
\text { Mean (s.d.) }\end{array}$ & $\begin{array}{l}\text { 12-month } \\
\text { follow-up } \\
\text { Mean (s.d.) }\end{array}$ \\
\hline GAF & $28.7(8.19)$ & $56.3(11.5)$ & $63(13.9)$ \\
\hline BPRS total score & 56.7 (5.2) & $32.5(6.9)$ & $30.9(6.4)$ \\
\hline SAI-E total score & $4.7(4.57)$ & $8.5(5.2)$ & $13.9(7.1)$ \\
\hline
\end{tabular}

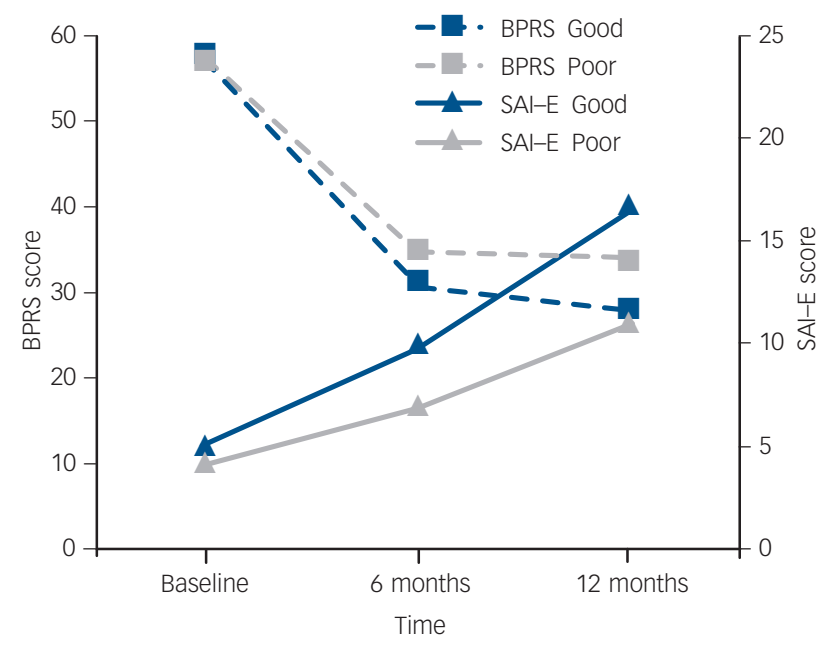

Fig. 1 Plot of psychopathological symptoms (Brief Psychiatric Rating Scale, BPRS) and insight (Scale for Assessment of Insight Expanded version, SAI-E) scores from baseline to 12-month follow-up by clinical outcome.

Baseline scores are similar but outcome groups diverge at the 6-month point Note that BPRS scores fall as symptoms improve and SAI-E scores rise as insight improves.

\begin{tabular}{|lc|}
\hline Table 3 Remission and relapse 1 year after first contact with \\
psychiatric services \\
\hline Outcome & $n(\%)$ \\
\hline Complete remission & $58(50)$ \\
Relapse & 2 \\
No relapse & 56 \\
\hline Remission with deficits & $57(50)$ \\
Relapse & 12 \\
No relapse & 45 \\
\hline
\end{tabular}

\section{Good and poor outcomes}

Table 3 summarises the rates of remission and relapse found in the cohort over the year of follow-up. Of the 115 patients assessed, half $(n=58)$ had experienced complete remission of symptoms and half $(n=57)$ experienced remission with deficits by the 12month follow-up. At the 6-month assessment, 1 patient had died, 15 had withdrawn and 12 could not be traced, and at 1 year there was 1 further death, 4 patients withdrew and a further 11 could not be traced. Fourteen patients (12\%) relapsed during the entire 12 -month follow-up period. Most of those assessed at 12 months ( $96 \%, n=110$ ) were found to satisfy the study criteria for schizophrenia at any time during the year of follow-up. In addition, $65 \%(n=75)$ were in regular contact for the monthly follow-up appointments.

\section{Insight and psychopathology}

Pearson correlation coefficients between insight and BPRS scores at baseline and follow-up assessment points were examined. At the baseline assessment there was no significant correlation between total BPRS score and total insight score. However, a significant albeit weak negative correlation between the relabelling dimension of the SAI-E and BPRS was observed (Pearson's $r=-0.2, P=0.04)$. In addition, the depression subscale score $($ mean $=6.5$, s.d. $=2.3)$ showed a weak positive correlation with SAI-E total score and illness awareness items $(r=0.17$ and $r=0.19$ respectively, $P \leqslant 0.05$ ).

At follow-up the pattern of associations was rather different: there was a moderate significant negative correlation between total BPRS score and total insight score at 1 year $(r=-0.3, P=0.007)$. Lower BPRS scores were significantly associated with increase in the awareness $(r=-0.35, P=0.01)$ and treatment dimensions $(r=-0.34, P=0.01)$ at 6 months and the awareness $(r=-0.4$, $P=0.01)$, relabelling $(r=-0.5, \quad P=0.01)$ and treatment dimensions $(r=-0.5, P=0.01)$ at 1 year. To find out whether changes in insight might be accounted for by improvement in clinical status, correlations between change scores in BPRS (baseline minus follow-up) and change scores in insight measures were obtained. The correlation coefficient was $r=0.3(P=0.01)$.

\section{Predictors of outcome}

Both regression analyses identified duration of untreated psychosis and early changes in insight and psychopathology as predictors of good outcome (Tables 4 and 5). Table 4 shows predictors of GAF and Table 5 shows predictors of clinically classified good outcome at 12 months. Duration of untreated psychosis is a significant predictor in both analyses in all four models, along with changes in psychopathology (BPRS) and insight (SAI-E) scores between baseline and 6 months (model 2). Interestingly, neither baseline insight nor baseline psychopathology was predictive of outcome (model 1). Similarly, changes between 6 months and 12 months were not related to outcome, with or without adjustment for baseline psychopathology/insight (models 3 and 4; Fig. 1).

\section{Components of insight}

We did not have sufficient statistical power to examine separately specific components of insight or symptom clusters. Nevertheless, exploratory analyses using GAF as the outcome measure indicated that at 6 months (model 2) the illness awareness dimension of the SAI-E was a significant predictor $(F=21.6, P<0.001$; adjusted $\left.R^{2}=0.330\right)$. Significant effects also emerged in model 3 with the illness awareness $(F=7.96, P=0.006)$ and treatment compliance ( $F=12.2, P=0.001)$ dimensions (but not relabelling).

\section{Discussion}

Three major findings emerged from this study. The first was that improvement in level of insight into illness during the early part of the illness predicted good outcome, regardless of how it was defined, in patients with schizophrenia. This is in spite of the fact that such improvement continued over the subsequent 6 months, whereas psychopathologic symptoms tended to plateau over this period (Fig. 1). This was shown in regression models which took 
Table 4 Predictors of good outcome in first-episode schizophrenia using Global Assessment of Functioning (GAF) score as the primary outcome: general linear model analysis

\begin{tabular}{|c|c|c|c|c|c|c|c|c|c|c|c|c|}
\hline & \multirow{2}{*}{$\begin{array}{l}\text { Model } \\
1^{\mathrm{a}} \text { Beta }\end{array}$} & \multirow{2}{*}{$\begin{array}{c}\text { Model } \\
2^{\mathrm{b}} \text { Beta }\end{array}$} & \multirow{2}{*}{$\begin{array}{l}\text { Model } \\
3^{\mathrm{C}} \text { Beta }\end{array}$} & \multirow{2}{*}{$\begin{array}{l}\text { Model } \\
4^{d} \text { Beta }\end{array}$} & \multicolumn{2}{|c|}{ Model 1} & \multicolumn{2}{|c|}{ Model 2} & \multicolumn{2}{|c|}{ Model 3} & \multicolumn{2}{|c|}{ Model 4} \\
\hline & & & & & $F$ & $P$ & $F$ & $P$ & $F$ & $P$ & $F$ & $P$ \\
\hline Age & -1.05 & 6.77 & 0.23 & 0.23 & 0.002 & 0.96 & 0.12 & 0.73 & 1.30 & 0.26 & 1.34 & 0.25 \\
\hline Gender $^{\mathrm{e}}$ & 0.57 & -1.13 & -0.40 & -0.77 & 0.04 & 0.85 & 0.19 & 0.66 & 0.02 & 0.88 & 0.08 & 0.77 \\
\hline Marital status ${ }^{f}$ & -1.76 & -3.37 & -0.99 & -0.42 & 0.32 & 0.57 & 1.60 & 0.21 & 0.12 & 0.73 & 0.02 & 0.89 \\
\hline DUP & -3.31 & -3.45 & -3.90 & -3.75 & 9.5 & $0.003^{*}$ & 11.50 & $0.001 *$ & 13.6 & $0.001^{*}$ & 12.2 & 0.001 \\
\hline Traditional healerg & 2.12 & 1.33 & 2.72 & 2.73 & 0.52 & 0.47 & 0.25 & 0.62 & 0.98 & 0.33 & 0.99 & 0.32 \\
\hline Education & -0.32 & -0.33 & -0.30 & -0.31 & 0.86 & 0.36 & 1.24 & 0.27 & 0.90 & 0.35 & 0.95 & 0.33 \\
\hline \multicolumn{13}{|l|}{ BPRS score } \\
\hline Baseline & 9.69 & & & 4.56 & 0.12 & 0.73 & & & & & 0.03 & 0.86 \\
\hline Change $0-6$ months & & -0.43 & & & & & 0.66 & $0.003^{*}$ & & & & \\
\hline Change 6-12 months & & & -0.30 & -0.30 & & & & & 0.66 & 0.08 & 3.10 & 0.08 \\
\hline \multicolumn{13}{|l|}{ SAI-E score } \\
\hline Baseline & 0.43 & & & 0.24 & 2.0 & 0.16 & & & & & 77 & 0.38 \\
\hline Change $0-6$ months & & 0.70 & & & & & 0.66 & $0.001^{*}$ & & & & \\
\hline Change 0-12 months & & & 0.24 & 0.24 & & & & & 1.66 & 0.20 & 1.61 & 0.21 \\
\hline \multicolumn{13}{|c|}{$\begin{array}{l}\text { BPRS, Brief Psychiatric Rating Scale; DUP, duration of untreated psychosis; SAI-E, Schedule for the Assessment of Insight - Expanded. } \\
\text { a. General linear model lusing GAF as outcome controlling for baseline BRS or SAl-E. } \\
\text { b. General linear model using GAF as outcome testing change in BPRS and SAI-E (baseline to } 6 \text { months) controlling for baseline SAl-E or BPRS respectively and other covariates. } \\
\text { c. General linear model using GAF as outcome testing change in BPRS or SAI-E (6-12 months) controlling for baseline BPRS or SAl-E and other covariates. } \\
\text { d. General linear model using GAF as outcome testing change in BPRS or SAI-E (6-12 months) additionally controlling for baseline SAl-E and BPRS. } \\
\text { e. Male } 0 \text {, female } 1 \text {. } \\
\text { f. Single } 1 \text {, other marital status } 0 \text {. } \\
\text { g. Traditional healer seen: yes } 1 \text {, no } 0 .\end{array}$} \\
\hline
\end{tabular}

\begin{tabular}{|c|c|c|c|c|c|c|c|c|c|c|c|c|}
\hline & \multirow{2}{*}{$\begin{array}{c}\text { Model } \\
1^{\text {a }} \mathrm{Cl}\end{array}$} & \multirow{2}{*}{$\begin{array}{c}\text { Model } \\
2^{\mathrm{b}} \mathrm{Cl}\end{array}$} & \multirow{2}{*}{$\begin{array}{l}\text { Model } \\
3^{\mathrm{C}} \mathrm{Cl}\end{array}$} & \multirow{2}{*}{$\begin{array}{l}\text { Model } \\
4^{d} \mathrm{Cl}\end{array}$} & \multicolumn{2}{|c|}{ Model 1} & \multicolumn{2}{|c|}{ Model 2} & \multicolumn{2}{|c|}{ Model 3} & \multicolumn{2}{|c|}{ Model 4} \\
\hline & & & & & OR & $P$ & OR & $P$ & OR & $P$ & OR & $P$ \\
\hline Age & $0.90-1.03$ & $0.88-1.03$ & $0.92-1.06$ & $0.92-1.06$ & 0.97 & 0.32 & 0.95 & 0.23 & 0.98 & 0.66 & 0.98 & 0.66 \\
\hline Gendere $^{\mathrm{e}}$ & $0.33-2.01$ & $0.23-1.68$ & $0.28-1.88$ & $0.28-1.92$ & 0.81 & 0.65 & 0.62 & 0.34 & 0.72 & 0.51 & 0.74 & 0.53 \\
\hline Marital status ${ }^{f}$ & $0.24-1.56$ & $0.16-1.28$ & $0.25-1.80$ & $0.23-1.81$ & 0.61 & 0.30 & 0.45 & 0.13 & 0.67 & 0.42 & 0.65 & 0.41 \\
\hline DUP & $0.99-1.00$ & $0.99-1.00$ & $0.99-1.00$ & $0.99-1.00$ & 0.99 & $0.04^{*}$ & 0.99 & $0.05^{*}$ & 0.99 & $0.03^{*}$ & 0.99 & $0.03^{*}$ \\
\hline Traditional healer ${ }^{g}$ & $0.31-1.79$ & $0.23-1.76$ & $0.32-2.17$ & $0.32-2.18$ & 0.75 & 0.51 & 0.64 & 0.39 & 0.83 & 0.72 & 0.84 & 0.72 \\
\hline Education & $0.85-1.06$ & $0.84-1.07$ & $0.85-1.07$ & $0.85-1.07$ & 0.95 & 0.37 & 0.95 & 0.23 & 0.95 & 0.42 & 0.95 & 0.42 \\
\hline \multicolumn{13}{|l|}{ BPRS score } \\
\hline Baseline & $0.93-1.08$ & $0.90-1.07$ & $0.92-1.08$ & $0.92-1.08$ & 1.00 & 0.95 & \multirow{3}{*}{0.95} & \multirow{3}{*}{$0.05^{\star}$} & & & & \\
\hline Change 0-6 months & & $0.89-1.0$ & & & & & & & & & & \\
\hline Change 6-12 months & & & $0.91-1.06$ & $0.91-1.03$ & & & & & 0.97 & 0.32 & 0.96 & 0.32 \\
\hline \multicolumn{13}{|l|}{ SAl-E score } \\
\hline Baseline & \multirow[t]{3}{*}{$0.94-1.13$} & \multirow{3}{*}{$1.04-1.23$} & $0.90-1.09$ & $0.90-1.09$ & 1.03 & 0.59 & \multirow{3}{*}{1.13} & \multirow{3}{*}{$0.006^{*}$} & & & 0.99 & 0.85 \\
\hline Change 0-6 months & & & & & & & & & & & & \\
\hline Change $0-12$ months & & & $0.96-1.09$ & $0.96-1.09$ & & & & & 0.84 & 1.03 & 1.03 & 0.42 \\
\hline $\begin{array}{l}\text { BPRS, Brief Psychiatric Rating } \\
\text { a. Logistic regression model us } \\
\text { b. Logistic regression model us } \\
\text { and other covariates. } \\
\text { c. Logistic regression model us } \\
\text { other covariates. } \\
\text { d. Logistic regression model us } \\
\text { e. Male } 0 \text {, female } 1 \text {. } \\
\text { f. Single } 1 \text {, other marital status } \\
\text { g. Traditional healer seen: yes } \\
\star P<0.05 \text {. }\end{array}$ & $\begin{array}{l}\text { ale; DUP, dura } \\
\text { gg clinical outcc } \\
\text { Ig clinical outc } \\
\text { gg clinical outcc } \\
\text { g clinical outc } \\
\text { no } 0 \text {. }\end{array}$ & $\begin{array}{l}\text { tion of untreat } \\
\text { ome as depen } \\
\text { :ome as depen } \\
\text { ome as depen } \\
\text { ome as depen }\end{array}$ & $\begin{array}{l}\text { ted psychosis; } \\
\text { ndent variable } \\
\text { ndent variable } \\
\text { ndent variable } \\
\text { ndent variable }\end{array}$ & $\begin{array}{l}\text {; GAF, Globa } \\
\text { controlling } \\
\text { testing cha } \\
\text { testing cha } \\
\text { testing cha }\end{array}$ & $\begin{array}{l}\text { baseline } \\
\text { in BPRS } \\
\text { in BPRS } \\
\text { in BPRS }\end{array}$ & $\begin{array}{l}\text { of Functio } \\
\text { SS or SAI } \\
\text { d SAI-E ( } \\
\text { A SAI-E ( } \\
\text { d SAI-E ( }\end{array}$ & $\begin{array}{l}\text { g; SAl-E } \\
\text { Seline to } \\
12 \text { month } \\
12 \text { montt }\end{array}$ & $\begin{array}{l}\text { nedule for } \\
\text { onths) con } \\
\text { ontrolling f } \\
\text { dditionally }\end{array}$ & $\begin{array}{l}\text { he Asses } \\
\text { olling fo } \\
r \text { baselin } \\
\text { ontrollin }\end{array}$ & $\begin{array}{l}\text { ent of Ir } \\
\text { seline S } \\
\text { Al-E or } \\
\text { baselir }\end{array}$ & $\begin{array}{l}\text { or BPRS } \\
\text { respec } \\
\text { ORS and }\end{array}$ & $\begin{array}{l}\text { pectively } \\
\text { and } \\
\text { E. }\end{array}$ \\
\hline
\end{tabular}

into account other factors including psychopathology. In England, Drake et al examined a sample of patients with first-episode non-affective psychosis recruited for a trial of cognitivebehavioural therapy and observed poor insight (assessed with a self-report insight scale) to be an independent predictor of relapse and readmission. ${ }^{10}$ This confirmed earlier work in studies using mostly cross-sectional designs and prevalent cases, ${ }^{14,20-27}$ plus prospective studies. ${ }^{8,28-30}$ Gharabawi et al carried out secondary analyses on an open-label multicentre trial of long-acting risperidone injection, and found that change on the insight item from the Positive and Negative Syndrome Scale (PANSS) for schizophrenia correlated with change in Clinical Global Impression- Severity (CGI-S) scores at 1 year, but not with quality of life. ${ }^{28}$ Saeedi et al reported on 278 patients admitted to a Canadian early psychosis service. ${ }^{29}$ The group was dichotomised on the basis of the PANSS insight score. Over 3 years those with persistently poor insight had persistently more symptoms and cognitive impairment.

In our study, insight at baseline did not predict remission without relapse or global functioning, but participants whose 
insight improved relatively early on in treatment had the better outcomes. The same pattern emerged for improvement in psychopathology: baseline scores failed to predict outcome, whereas improvement over the first 6 months did. Later improvement (6-12 months) in insight and psychopathology did not predict outcome even though it was more proximal to it. In Ireland, Crumlish et al reported that early improvement in insight on a self-report scale predicted suicidal behaviour when assessed at 4 years. ${ }^{31}$ We await report of whether insight predicted better general outcome in this sample.

\section{Quality of outcome}

Our second finding was that during the follow-up period remission was common and relapses rare. Almost half of the patients had full remission of symptoms over the course of the 12 -month follow-up. This rate of remission (50\%) is midway between rates reported from urban and rural Chandigarh as part of the DOSMeD project but lower than the 69\% recorded in Vellore in SOFACOS in the early 1980 s. $^{16-18}$ This is consistent with the 'favourable outcome' hypothesis in low- and middleincome countries, ${ }^{18,32-35}$ but see Cohen et al ${ }^{36}$ and Leff $^{37}$ for a debate on this question.

\section{Duration of untreated psychosis}

Our third finding is the significant association between DUP and both outcome measures, even after changes in insight and psychopathology were controlled for (see Drake et al). ${ }^{38}$ Patients with longer DUP were less likely to achieve full remission. This is in line with many published studies in various settings including low- and middle-income countries. ${ }^{39-41}$ In our study the good outcome and poor outcome groups had a mean DUP of 67.1 weeks and 122.5 weeks respectively. It is not certain that reducing this period would necessarily improve outcome, but this is surely a worthwhile issue for research and clinical development. We did not find any gender effects on outcome in this study. Superior outcome in women was noted both in DOSMeD and other studies from India and in rural China, although not in Nigeria or Colombia. ${ }^{35,40,42-44}$

\section{Insight, psychopathology and culture}

We found fairly consistent associations between insight and psychopathology. Our baseline findings using the expanded BPRS and SAI-E showed weak but significant inverse correlations between total BPRS score and the relabelling dimension. ${ }^{5,45}$ However, at follow-up all three dimensions of insight (awareness, compliance and relabelling) and total insight scores showed predictably significant although weak relationships with psychopathology. This is in line with most studies in a variety of settings, including India, ${ }^{6,29,46-48}$ but see Drake et al who found that paranoia and delusions specifically were unrelated to global insight. ${ }^{45}$ Studies in our cohort using quantitative and qualitative methods suggest that early change in insight or remaining within the existing 'collaborative social world' may have benefits. ${ }^{19}$ One clinical implication is that efforts to improve insight taking account of local cultural factors could yield benefits in outcomes and might relate to the supposedly superior prognosis of psychosis in settings such as those in south India.

\section{Methodological issues}

The participants in this study were located in a mental health service centred on a large hospital. This may represent a selection bias. However, this is likely to have resulted in a more severely affected patient cohort than one derived from community-based case ascertainment. Initially, $29 \%$ had to be excluded, mostly owing to florid psychotic disturbance rendering formal assessment impossible. Withdrawal rates were low, reflecting in large part the influence of intact family structures which support patients and value medical treatment. Outcome was categorised relatively crudely to assist comparison with other studies, yet the continuous and categorical outcomes yielded highly consistent findings. The clinically defined categorical outcome was made in part by the psychiatric researcher (B.S.), who also participated in the initial and follow-up ratings of psychopathology (including insight) and measurement of DUP, so may have been biased. However, the research nurse (S.J.) who rated GAF outcome was unaware of DUP status. This method ensured that at least one of the outcome measures is unlikely to have been biased by knowledge of DUP or other baseline factors. Again, the consistency in the findings regarding predictors of outcome provides reassurance that such observer bias was minimal. Finally, we were unable to measure the extent to which aspects of culture shape insight and hence outcome of schizophrenia in this study in the absence of contemporaneous control data from other countries or settings.

\section{Balasubramanian Saravanan, MD, Institute of Psychiatry, London, UK, and Christian Medical College, Vellore, India; K. S. Jacob, PhD, MD, Shanthi Johnson Christian Medical College, Vellore, India; Martin Prince, MD, MRCPsych, Dinesh Bhugra, PhD, FRCPsych, Anthony S. David, MD, FRCP, FRCPsych, Institute of Psychiatry, London, UK \\ Correspondence: Professor Anthony David, Section of Cognitive Neuropsychiatry, PO Box 68, Institute of Psychiatry, King's College London, Denmark Hill, London SE5 8AF, UK. Email: anthony.david@kcl.ac.uk \\ First received 15 May 2009, final revision 3 Dec 2009, accepted 8 Feb 2010}

\section{Funding}

B.S. was supported by a grant from the Wellcome Trust. (Ref. no. 064699).

\section{Acknowledgements}

We thank the participants and support staff of Christian Medical College, Vellore, for their cooperation and commitment to completion of the study.

\section{References}

1 World Health Organization. Report of the International Pilot Study of Schizophrenia. WHO, 1973.

2 Wilson WH, Ban TA, Guys W. Flexible system criteria in chronic schizophrenia. Compr Psychiatry 1986; 27: 259-65.

3 Amador XF, David AS (eds). Insight and Psychosis: Awareness of Illness in Schizophrenia and Related Disorders (2nd edn). Oxford University Press, 2004.

4 Saravanan B, Jacob KS, Prince M, Bhugra D, David AS. Culture and insight revisited. Br J Psychiatry 2004; 184: 107-9.

5 Saravanan B, Jacob KS, Johnson S, Prince M, Bhugra D, David AS. Assessing insight in schizophrenia: East meets West. Br J Psychiatry 2007; 190: 243-7.

6 David AS. The clinical importance of insight: an overview. In Insight and Psychosis: Awareness of Illness in Schizophrenia and Related Disorders (2nd edn) (eds XF Amador, AS David): 359-92. Oxford University Press, 2004.

7 Lincoln TM, Lullmann E, Rief W. Correlates and long-term consequences of poor insight in patients with schizophrenia. A systematic review. Schizophr Bull 2007; 33: 1324-42.

8 David A, van Os J, Jones P, Harvey I, Foerster A, Fahy T. Insight and psychotic illness. Cross-sectional and longitudinal associations. Br J Psychiatry 1995; 167: $621-8$

9 van Os J, Fahy TA, Jones $\mathrm{P}$, Harvey I, Sham $\mathrm{P}$, Lewis $\mathrm{S}$, et al Psychopathological syndromes in the functional psychoses: associations with course and outcome. Psychol Med 1996; 26: 161-76. 
10 Drake RJ, Dunn G, Tarrier N, Bentall RP, Haddock G, Lewis SW. Insight as a predictor of the outcome of first episode non-affective psychosis in a prospective cohort study in England. J Clin Psychiatry 2007; 68: 81-6.

11 Statistical Handbook of Tamilnadu. Tamilnadu Statistics At A Glance. Ministry of Home Affairs, 2006 (http//census.tn.nic.in).

12 Spitzer RL, Williams JBW, Gibbon M. The Structured Clinical Interview for DSM-III-R-Patient Version (SCID-P). American Psychiatric Association, 1990.

13 David A, Buchanan A, Reed A, Almeida O. The assessment of insight in psychosis. Br J Psychiatry 1992; 161: 599-602.

14 Sanz M, Constable G, Lopez-Ibor I, Kemp R, David AS. A comparative study o insight scales and their relationship to psychopathological and clinical variables. Psychol Med 1998; 28: 437-46.

15 Ventura JA, Lukoff D, Neuchterlein KH, Liberman RP, Green MF, shaner A. Brief Psychiatric Rating Scale Expanded Version 4.0: Scales Anchor Points and Administration Manual. UCLA Publications, 1993.

16 Indian Council of Medical Research. Multicentered Collaborative Study of Factors Associated with the Course and Outcome of Schizophrenia: Final Report. ICMR, 1988.

17 Verghese A, John JK, Rajkumar S, Richard J, Sethi BB, Trivedi JK. Factors associated with the course and outcome of schizophrenia in India. Results of a two-year multicentre follow-up study. Br J Psychiatry 1989; 154: 499-503.

18 Jablensky A, Sartorius N, Emberg G, Anker M, Korten A, Cooper JE, et al. Schizophrenia: manifestations, incidence and course in different cultures: World Health Organization ten country study. Psychol Med 1992 (suppl 20): $1-97$

19 Saravanan B, Jacob KS, Deepak MG, Bhugra D, Prince M, David A. Perceptions about psychosis and psychiatric services: a qualitative study from Vellore, India. Soc Psychiatry Psychiat Epidemiol 2008; 43: 231-8.

20 McEvoy JP, Applebaum PS, Apperson L, Geller JL, Freter S. Why must some schizophrenic patients be involuntarily committed? The role of insight. Compr Psychiatry 1989; 30: 13-7.

21 McEvoy JP, Apperson LJ, Appelbaum PS, Ortlip P, Brecosky J, Hammill K, et al. Insight in schizophrenia: its relationship to acute psychopathology. J Nerv Ment Dis 1989; 177: 43-7.

22 Amador XF, Strauss DH, Yale SA, Flaum MM, Endicott J, Gorman NK. Assessment of insight in psychosis. Am J Psychiatry 1993; 150: 873-9.

23 Amador XF, Flaum M, Andreasen NC, Strauss DS, Yale SA, Clark SC. Awareness of illness in schizophrenia and schizoaffective and mood disorders. Arch Gen Psychiatry 1994; 151: 826-36.

24 Cuesta MJ, Peralta V. Lack of insight in schizophrenia. Schizophr Bull 1994; 20: 359-66.

25 Jørgensen P. Recovery and insight in schizophrenia. Acta Psychiatr Scand 1995; 92: 436-40.

26 Kemp RA, Lambert TJ. Insight in schizophrenia and its relation to psychopathology. Schizophr Res 1995; 18: 21-8.

27 Cuesta MJ, Peralta V, Zarzuela A. Reappraising insight in psychosis. Multiscale longitudinal study. Br J Psychiatry 2000; 177: 233-40.

28 Gharabawi GM, Lasser RA, Bossie CA, Zhu Y, Amador X. Insight and its relationship to clinical outcomes in patients with schizophrenia or schizoaffective disorder receiving long-acting risperidone. Int Clin Psychopharmacol 2006; 21: 233-40.

29 Saeedi $\mathrm{H}$, Addington J, Addington D. The association of insight with psychotic symptoms, depression and cognition in early psychosis: a 3 year follow-up. Schizophr Res 2007; 89: 123-8.
30 Ceskova E, Prikryl R, Kasparek T, Kucerova H. Insight in first episode schizophrenia. Int J Psychiatry Clin Pract 2007; 1-5.

31 Crumlish N, Whitty P, Kamali M, Clarke M, Browne S, McTigue O, et al. Early insight predicts depression and attempted suicide after 4 years in firstepisode schizophrenia and schizophreniform disorder. Acta Psychiatr Scand 2005; 112: 449-55.

32 Lin M, Kleinman A. Psychopathology and clinical course of schizophrenia: a cross-cultural perspective. Schizophr Bull 1988; 14: 555-67.

33 Leff J, Sartorius N, Jablensky A, Korten A, Ernberg G. The International Pilot Study of Schizophrenia: five year follow-up findings. In Search for the Causes of Schizophrenia, vol 2 (eds H. Hafner, WF Guttaz): 57-66. Springer Verlag, 1990

34 Menezes PR, Rodrigues LC, Mann AH. Predictors of clinical and social outcomes after hospitalization in schizophrenia. Eur Arch Psychiat Clin Neurosci 1997; 247: 137-45.

35 Hooper K, Harrison G, Janca A, Sartorius N (eds). Recovery from Schizophrenia: An International Perspective. Oxford University Press, 2007.

36 Cohen A, Patel V, Thara R, Gureje O. Questioning an axiom: better prognosis for schizophrenia in the developing world? Schizophr Bull 2008; 34: 229-44.

37 Leff J. Comment on paper by Cohen, Patel, Thara, and Gureje. Schizophr Bull 2008; 34: 251-2.

38 Drake RJ, Haley CJ, Akhtar S, Lewis SW. Causes and consequences of duration of untreated psychosis in schizophrenia. Br J Psychiatry 2000; 177: 511-5.

39 Marshall M, Lewis D, Lockwood A, Drake R, Jones P, Croudace T. Association between duration of untreated psychosis and outcome in cohorts of firstepisode patients: a systematic review. Arch Gen Psychiatry 2005; 62: 975-83.

40 Ran $\mathrm{M}$, Xiang $\mathrm{M}$, Huang $\mathrm{M}$, Shan $\mathrm{Y}$. Natural course of schizophrenia: 2-year follow-up study in a rural Chinese community. Br J Psychiatry 2001; 178: $154-8$.

41 Farooq $\mathrm{S}$, Large $\mathrm{M}$, Nielssen $\mathrm{O}$, Waheed $\mathrm{W}$. The relationship between duration of untreated psychosis and outcome in low and middle income countries: a systemic review and meta analysis. Schizophr Res 2009; 109 15-23.

42 Thara R, Rajkumar S. Gender differences in schizophrenia: results of a followup study from India. Schizophr Res 1992; 7: 65-70.

43 Thara R, Henrietta M, Joseph A, Rajkumar S, Eaton WW. Ten year course of schizophrenia - the Madras Longitudinal Study. Acta Psychiatr Scand 1994; 90: 329-36.

44 Ohaeri JU. Long term outcome of treated schizophrenia in a Nigerian cohort. Retrospective analysis of 7 year follow-ups. J Nerv Ment Dis 1993; 181: 514-6.

45 Drake RJ, Pickles A, Bentall RP, Kinderman P, Haddock G, Tarrier N, et al. The evolution of insight, paranoia and depression during early schizophrenia. Psychol Med 2004; 34: 285-92.

46 Kulhara P, Chakrabarti S, Basu D. Insight and psychosis: I. An empirical inquiry. Indian J Soc Psychiatry 1992; 8: 40-4.

47 Aga VM, Agarwal AK, Gupta SC. The relationship of insight to psychopathology in schizophrenia: a cross sectional study. Indian J Psychiatry 1995; 37: 129-35.

48 Mintz AR, Dobson KS, Romney DM. Insight in schizophrenia: a meta-analysis. Schizophr Res 2003; 61: 75-88. 